\title{
PREVALENCE, SPECIATION AND ANTIBIOTIC RESISTANCE PROFILES OF COAGULASE NEGATIVE STAPHYLOCOCCI ISOLATES FROM CLINICAL SAMPLES
}

\author{
Geetanjali Tupakula1, R. Kondal Rao², G. Ravindranadh 3 , GVK Varshith 4 \\ ${ }^{1}$ Assistant Professor, Department of Microbiology, ACSR Government Medical College, Nellore. \\ 2 Professor and HOD, Department of Microbiology, Kakatiya Medical College, Warangal. \\ ${ }^{3}$ Professor and HOD, Department of Anatomy, NRIIMS, Visakhapatnam. \\ 4Student, Oakridge International School.
}

\section{ABSTRACT}

\section{BACKGROUND}

Coagulase-Negative Staphylococci (CONS) are opportunistic pathogens and have become major cause of nosocomial infections. The present study was undertaken to speciate the clinical isolates of CONS and study their antibiogram.

\section{MATERIALS AND METHODS}

Samples were collected from various sources under aseptic conditions based on standard guidelines from patients of surgical, medical, orthopaedic wards, MGM Hospital, Warangal and its satellite hospitals. Total 210 samples were collected and the prevalence of CONS by cultural and biochemical methods was studied. Antibiotic susceptibility patterns were determined by KirbyBauer disc diffusion method as per CLSI guidelines. Speciation of CONS was done by slide using tube coagulase test, ornithine decarboxylase test, urease activity, trehalose fermentation, mannitol fermentation and novobiocin resistance test.

\section{RESULTS}

Out of 210 samples tested, 100 (47.61\%) were CONS and majority of the CONS isolates were hospital acquired infections (68\%; $\mathrm{n}=$ 68). Highest number of CONS isolates were observed in catheters (32/42) followed by wound (38/68), blood samples (14/39), urine (15/55) and CSF (1/6). Among the 100 CONS isolates, S. epidermidis was the commonest species isolated found in $48 \%(\mathrm{n}=$ 48), followed by S. saprophyticus $(20 \% ; n=20)$, S. haemolyticus $(15 \% ; n=15)$, S. hominis $(14 \% ; n=14)$ and S. caprae $(3 \% ; n=3)$. Antibiotic susceptibility testing showed the maximum number of isolates was resistant to amoxicillin (70\%), cotrimoxazole (65\%), ciprofloxacin (61\%) and penicillin (53\%), while majority of the CONS isolates were methicillin sensitive (81\%) and vancomycin sensitive (69\%).

\section{CONCLUSION}

The results of the present study reiterate the need for proper species identification and antibiotic susceptibility patterns for proper management of nosocomial infections caused by CONS and also for epidemiological purpose.

\section{KEYWORDS}

Coagulase-Negative Staphylococci, Speciation, Antibiogram, Antibiotic Susceptibility.

HOW TO CITE THIS ARTICLE: Tupakula G, Rao RK, Ravindranadh G, et al. Prevalence, speciation and antibiotic resistance profiles of coagulase negative staphylococci isolates from clinical samples. J. Evolution Med. Dent. Sci. 2017;6(26):2134-2136, DOI: $10.14260 / \mathrm{Jemds} / 2017 / 463$

\section{BACKGROUND}

The importance of Coagulase Negative Staphylococci (CONS) in causing human infection is well documented. Coagulase negative staphylococci are important causative agents of $10 \%$ of pyogenic infections in hospitals which include a range of infections like surgical wound sepsis, bacteraemia, Native Valve Endocarditis (NVE) and prosthetic valve endocarditis, osteomyelitis, pyoarthritis, peritonitis, mediastinitis, prostatitis, infection of vascular grafts and pacemakers, infective intravascular catheters, cerebrospinal fluid shunts, orthopaedic devices and urinary tract infections. Normally commensals on the skin and mucous membrane, coagulase negative staphylococci become opportunistic pathogens in

Financial or Other, Competing Interest: None.

Submission 07-02-2017, Peer Review 18-03-2017,

Acceptance 24-03-2017, Published 30-03-2017.

Corresponding Author:

Dr. Geetanjali Tupakula,

H. No. 24-3-357, Sujathamma Colony,

Main Road, A. K. Nagar, Nellore-524004.

E-mail: drgeeta1129@gmail.com

DOI: $10.14260 /$ jemds $/ 2017 / 463$ conditions of lowered resistance in the local area. As this organism occupies more than $10 \%$ of hospital infections, antibiotic sensitivity pattern also showed a change and increased degree of antibiotic resistance is being documented. As there are a number of species of coagulase negative staphylococci after their isolation from various specimens received, they were speciated and their antibiogram was studied. Since most of the infections caused by coagulase negative staphylococci are hospital associated, it is extremely relevant to study the resistance pattern so that it would serve as a useful guide to the healthcare providers. Hence, the study attempted to speciate the clinical isolates of coagulase negative staphylococci and to study their antibiogram.

\section{MATERIALS AND METHODS}

The samples were collected from outpatients and inpatients of surgical, medical, orthopaedic wards, MGM Hospital, Warangal and its satellite hospitals were included in the present study; 210 samples were collected from infected postoperative cases, infected burns, infected wounds from traumatology unit, diabetic foot, gangrene, non-healing 
ulcers, pyoderma and impetigo, patients with intravenous cannulae were chosen as subjects of study after obtaining approval from the Institutional Ethics Committee and written informed consent was taken from the patients. The comorbid, immunosuppressed patients, patients with Diabetes mellitus, patients with Malnutrition and on Steroid therapy, patients with Hypoproteinaemia, patients with Malignancies and on Antimalignancy drugs was completely excluded.

Serous, serosanguinous or purulent discharge from the ulcers or wounds was collected with sterile swabs from the base of the lesions without touching the surrounding area of skin. In case of spreading lesions of skin and subcutaneous tissue (such as progressive gangrene), the material was collected from the active margins of the lesions rather than from central portion. When the exudate was minimal, gentle pressure was applied at the base of the lesion and the expressed discharge was collected with the swab. Care was taken to avoid topical application of any antibiotics at least 24 hrs. before collection of the sample. Two swabs were collected from each patient, one for making smears and another for culture. Swabs sterilised by autoclaving were used to collect specimens in preference to swabs sterilised by hot air oven.

The samples were processed as per the standard reference procedures (Bailey and Scott 2007). ${ }^{1}$ Gram positive cluster forming staphylococci which are catalase positive, oxidase negative, bacitracin resistant, furazolidone sensitive and fermentative by the oxidation fermentation test were identified as staphylococcal. The staphylococci strains were subjected to slide and tube coagulase test and those strains which were negative by both methods were identified as Coagulase Negative Staphylococci (CONS). The identification of all the species of CONS isolated was done by using various standard biochemical tests. Antibiogram of isolates was performed using Kirby-Bauer method (Clinical and Laboratory Standards Institute (CLSI) guidelines). ${ }^{2}$

\section{RESULTS}

\begin{tabular}{|c|c|c|}
\hline \multirow{2}{*}{$\begin{array}{c}\text { Total Number of } \\
\text { Test Samples } \\
210\end{array}$} & \multicolumn{2}{|c|}{$\begin{array}{c}\text { Coagulase Negative } \\
\text { Staphylococci (CONS) }\end{array}$} \\
\cline { 2 - 3 } & Number & Percentage \\
\cline { 2 - 3 } & 100 & 47.61 \\
\hline \multicolumn{2}{|c|}{ Table 1. Number and Percentage of Coagulase Negative } \\
Staphylococci Isolates in the Present Study
\end{tabular}

Table 1 shows number and percentage of CONS isolates in the present study; out of 210 samples tested, 100 (47.61\%) of CONS are isolated.

\begin{tabular}{|c|c|c|c|}
\hline Sl. No. & Name of the Species & Number & Percentage \\
\hline 1. & S. epidermidis & 48 & 48 \\
\hline 2. & S. saprophyticus & 20 & 20 \\
\hline 3. & S. haemolyticus & 15 & 15 \\
\hline 4. & S. hominis & 14 & 14 \\
\hline 5. & S. caprae & 3 & 3 \\
\hline $\begin{array}{r}\text { Table 2. Number and Percentage of Coagulase Negative } \\
\text { Staphylococci Species found in the 100 Isolates } \\
\hline\end{array}$
\end{tabular}

Table 2 shows speciation of Coagulase negative staphylococci isolates. Out of 100 isolates of Coagulase negative staphylococci, 48 (48\%) isolates were identified as
S. epidermidis; 20 (20\%) were identified as S. saprophyticus; 15 (15\%) were identified as S. haemolyticus; 14 (14\%) were identified as S. hominis; 3(3\%) were identified as S. caprae.

\begin{tabular}{|c|c|c|c|c|c|}
\hline \multirow{2}{*}{ Sl. No. } & \multirow{2}{*}{ Antibiotic } & \multicolumn{2}{|c|}{ Resistant } & \multicolumn{2}{c|}{ Sensitive } \\
\cline { 3 - 6 } & & No. & $\mathbf{\%}$ & No. & \% \\
\hline 1. & Penicillin & 42 & 61.76 & 26 & 38.23 \\
\hline 2. & Oxacillin & 23 & 33.82 & 45 & 66.17 \\
\hline 3. & Ciprofloxacin & 48 & 70.58 & 20 & 29.41 \\
\hline 4. & Vancomycin & 16 & 23.52 & 52 & 76.47 \\
\hline 5. & Cotrimoxazole & 59 & 86.76 & 9 & 13.23 \\
\hline 6. & Amoxicillin & 56 & 82.35 & 12 & 17.64 \\
\hline \multicolumn{6}{|c|}{ Table 3. Antibiogram of Coagulase } \\
negative Staphylococci under Study \\
\hline
\end{tabular}

\section{DISCUSSION}

In the present study (Table 1), 100 CONS isolates were obtained by processing 210 clinical samples (47.61\%). These results indicate the prominent place occupied by CONS in infection and more so in the hospital infections.

The percentage isolation of CONS from clinical samples is not available in similar studies; Shoba et al 2005 collected 205 swabs from the various places in the hospital and from healthy hospital staff. ${ }^{3}$ They obtained a percentage of $31.7 \%$; surprisingly, all the staphylococcal isolates in their study were CONS. This study represents the magnitude of the hospital source, from which infection can be transmitted to vulnerable patients through various invasive procedures if proper care and aseptic precautions are not taken.

The predominant species of CONS in present study was S. epidermidis (Table 2); 48 strains of S. epidermidis were isolated. S. epidermidis was the most commonly encountered species among the CONS. Its prevalence as nosocomial pathogen was very much related to medical procedures and practices than the capacity of the organism to establish infection (Kloos WE and Bannerman TL). ${ }^{4}$ Carlos et al identified an endemic strain of S. epidermidis in the hospital producing bacteraemia in the neonantal intensive care unit. ${ }^{5}$ S. epidermidis is a notorious slime producer and easily establishes biofilm on polymers within which the organism can limit the effectiveness of antibiotic therapy and multiplies further as reported by Shoba et al 2005. Staphylococcus epidermidis is prevalent in $49.23 \%$ of hospital sites including the skin of the healthcare providers; $14 \%$ of these strains were oxacillin resistant, thus S. epidermidis can be termed as an important hospital pathogen and hospital infection control programs should include eradication of this organism from the hospital sites.

$20 \%$ of CONS isolates were identified as S. saprophyticus (Table 2). This organism unlike S. epidermidis was more a member of the community. It is a common organism isolated from urine from community acquired urinary infections in young sexually active females. Establsihment of $\mathrm{S}$. saprophyticus as pathogen requires repeated careful processing and quantitative urine cultures as the organism inhabits the normal urethra and perineal skin, it is likely to contaminate urine sampels during collection. S. saprophyticus has high capacity to adhere and colonise on surfaces, but unlike S. epidermidis it is a poor producer of slime (Kleeman KT et al). ${ }^{6}$

In the present study, $15 \%$ of isolates were identified as S. haemolyticus (Table 2). S. haemolyticus is also part of the 
human normal skin flora. It has been documented as a cause of nosocomial bacterimias. Vancomycin resistance has been reported in this organism as well as multidrug resistance. The presence of multiple antibiotic resistant $\mathrm{S}$. haemolyticus in the hospital environment and transmission of resistant clones through the hands of healthcare workers have been documented by several investigators using molecular methods (Kloos WE and George CG). ${ }^{7}$ Compared to $\mathrm{S}$. epidermidis this organism colonises in much fewer numbers and less commonly incorporated in clinical illness.

S. hominis isolates were $14 \%$ among the total CONS isolated in the present study. Among the 14 strains 9 were from wounds, 2 strains each from blood and urine and 1 from catheter. This species is a comensal of the skin of humans and has occasinally been isolated from infections as a low-grade pathogen; however, under antibiotic pressure it is known to develop resistance more easily and readily (Kloos WE and Musselwhite MS). ${ }^{8}$

S. caprae strains (3\%) occupied least importance among the total CONS isaolates in the present study (Table 2); among them 2 are from wound and 1 from urine. S. caprae is rarely cultured from clinicial specimen when compared to $\mathrm{S}$. epidermidis. It has been reported in association with bone and joint infection (Banerjee SN et al and Richards MJ et al). 9,10 Strains of S. caprae isolated from humans are known to contain a 5 gene ica operon that code for the gene products in biofilm formation. The gene products exhibit subtotal aminoacid identity with those of S. epidermidis.

The antibiogram of Coagulase negative staphylococci (Table 3) under study shows that out of the 68 isolates of CONS 26 (38.23\%) were sensitive to Penicillin and 42 $(61.76 \%)$ were resistant; $45(66.17 \%)$ were sensitive to Oxacillin and 23 (33.82\%) were resistant; 20 (29.41\%) were sensitive to Ciprofloxacin and 48 (70.58\%) were resistant; 52 (76.47\%) were sensitive to Vancomycin and 16 (23.52\%) were resistant; 9 (13.23\%) were sensitive to Cotrimoxazole and $59(86.76 \%)$ were resistant; $12(17.64 \%)$ were sensitive to Amoxicillin and $56(82.35 \%)$ were resistant.

\section{CONCLUSION}

In the present study, Coagulase negative Staphylococci were the most predominant organisms $(210 / 100 ; 47.61 \%)$ in various clinical samples and thus Coagulase Negative Staphylococci have been increasingly gaining importance in hospital infections compared to E. coli, Klebsiella, MRSA and Pseudomonas. Majority of the Isolates were from IV catheters $(76.19 \%)$ stressing the need for more aseptic precautions in ICU settings. Most predominant species of CONS in this study was S. epidermidis followed by S. saprophyticus. Among the 68 isolates of CONS Penicillin resistance is $61.76 \%$, Oxacillin resistance is $33.82 \%$, Ciprofloxacin resistance is $70.58 \%$, Vanocomycin resistance is $23.52 \%$, Cotrimoxazole resistance is $86.72 \%$ and Amoxicillin resistance is $82.35 \%$. Hence, Vancomycin is the drug of choice for the treatment of nosocomial infections caused by CONS and restricted and choicest use of this antibiotic can greatly reduce the risk of acquisition of resistance by the organism.

\section{REFERENCES}

[1] Forbes BAA, Sahm DF, Weissfeld AS. Bailey \& scott's diagnostic microbiology. $12^{\text {th }}$ edn. Elsevier 2007:21734.

[2] Bauer AW, Kirby WM, Sherris JC, et al. Antibiotic susceptibility testing by a standardized single disk method. Am J Clin Pathol 1966;45(4):493-6.

[3] Shobha KL, Rao PS, Thomas J. Survey of staphylococcus isolates among hospital personnel, environment and their antibiogram with special emphasis on methicillin resistance. Indian J Med Microbiol 2005;23(3):186-8.

[4] Kloos WE, Bannerman TL. Update on clinical significance of coagulase-negative staphylococci. Clin Microbiol Rev 1994;7(1):117-40.

[5] Carlos CC, Ringertz S, Rylander M, et al. Nosocomial staphylococcus epidermidis septicaemia among very low birth weight neonates in an intensive care unit. J Hosp Infect 1991;19(3):201-7.

[6] Kleeman KT, Bannerman TL, Kloos WE. Species distribution of coagulase-negative staphylococcal isolates at a community hospital and implications for selection of staphylococcal identification procedures. J Clin Microbiol 1993;31(5):1318-21.

[7] Kloos WE, George CG. Identification of staphylococcus species and subspecies with the MicroScan Pos ID and rapid Pos ID panel systems. J Clin Microbiol 1991;29(4):738-44.

[8] Kloos WE, Musselwhite MS. Distribution and persistence of staphylococcus and micrococcus species and other aerobic bacteria on human skin. Applied Microbiology 1975;30(3):381-95.

[9] Banerjee SN, Emori TG, Culver DH, et al. Secular trends in nosocomial primary bloodstream infections in United States, 1980-1989. National nosocomial infection surveillance system. Am J Med 1991;91(3B):86S-9S.

[10] Richards MJ, Edwards JR, Culver DH, et al. Nosocomial infections in combined medical-surgical intensive care units in the United States. Infect Control Hosp Epidemiol 2000;21(8):510-5. 